\title{
Effect of safran, safranal and crocin which are active ingredients of Saffron (Crocus) on erythrocyte fragility and hematological parameters in carbon tetrachloride intoxicated rats
}

\author{
Okan Arihan ${ }^{1, *}$, Gokhan Oto ${ }^{2}$, Irfan Bayram ${ }^{3}$, Ibrahim Aras $^{3}$ \\ ${ }^{1} Y$ uquncu Yil University, Faculty of Medicine, Department of Physiology, V an, Turkey \\ ${ }^{2} Y$ uzuncu Yil University, Faculty of Medicine, Department of Pharmacology, Van, Turkey \\ ${ }^{3}$ Yuzuncu Yil University, Faculty of Medicine, Department of Pathology, Van, Turkey
}

\begin{abstract}
Carbon tetrachloride is a toxic chemical and well known for its carcinogenic property. Intoxication with carbon tetrachloride causes serious liver injury and it is used as an experimental model for triggering liver related diseases. Saff ron (Crocus) species are well known bulbous ornamental and aromatic plants. Many of the saffron species are used in ethnomedicinal practices. In addition both saffron species and their ingredients are also subject to scientific research. In this study 72 rats were divided into 9 groups ( $n=8$ in each group). Groups were set as control, olive oil, carbon tetrachloride, safran, safranal, crocin, carbon tetrachloride + safranal, carbon tetrachloride + crocin. Administrations were conducted for 7 days. Erythrocyte osmotic fragility and some selected hematological parameters were assessed. Results state significant increase in erythrocyte fragility due to carbon tetrachloride and amelioration due to active ingredients of saffron. Among hematocrit, hemoglobin and red blood cell count parameters only significant alteration was observed in safran with an increase in red blood cell count. Different administration schemes can be evaluated in future studies in order to assess detailed impact of saffron constituents on hematological parame ters and erythrocyte integrity.
\end{abstract}

Key Words: Saffron, carbon tetrachloride, erythrocyte fragility, safran, safranal, crocin

\section{Introduction}

Carbon tetrachloride $\left(\mathrm{CCL}_{4}\right)$ is a transparent, nonflammable toxic chemical which may quickly evaporate from its liquid form (1). Experimental or unintended exposure to $\mathrm{CCL}_{4}$ causes serious hazards to organisms. It is a cytotoxic xenobiotic. Cellular damage due to $\mathrm{CCL}_{4}$ is caused by augmented lipid peroxidation. $\mathrm{CCL}_{4}$ transforms into $\mathrm{CCL}_{3}$ which is a free radical (2). Main outcome of $\mathrm{CCL}_{4}$ exposure is hepatotoxicity. Experimental studies reveal that $\mathrm{CCL}_{4}$ causes hepatic fatty degeneration, mononuclear cell infiltration, fibrosis, degeneration in hepatocytes, cirrhosis and cancer (3). Since liver degeneration due to $\mathrm{CCL}_{4}$ resembles cirrhosis advance in humans, $\mathrm{CCL}_{4}$ is widely used as a chemical agent in experimental studies in rodents. Oxidative stress is an important counterpart in this liver toxicity caused by $\mathrm{CCL}_{4}$. Various synthetic and natural compounds mainly from plants were tested against $\mathrm{CCL}_{4}$ toxicity (4).
Crocus sativus is a member of Iridaceae plant family. It is known as saffron. It is widespread in Turkey and Iran and used as food and for cosmetic purposes. In addition, it is used in ethnomedicine as anti-spasmodic, aphrodisiac, anti-convulsant, stomachic and in treatment of diseases such as dysentery, cholera, depression and insomnia. Scientific studies on this plant and its active ingredients revealed that it has antidepressant, anti-convulsant, anti-inflammatory, antidiabetic and anti-tumoral activity (5-8). Saffron and its ingredients; safranal, crocin and crocetin are proven to exert anti-oxidant activity in many studies (9-14).

In order to test activity hazardous or protective activity of different chemicals and products of natural origin there are various existing models such as cytotoxic, anti-tumoral and anti-oxidant activity. Erythrocyte osmotic fragility is another test for assessment of membrane integrity and resistance against damage triggered by osmosis (15). Although it is simple and easy to assess, it 
provides valuable information. Processes occurred such as increased lipid peroxidation or augmented protein carbonylation due to exposed chemicals or disease situations attenuate durability of erythrocytes against such hazardous effects. Studies concerning impact of oxidative stress on osmotic fragility of erythrocytes are present in literature. Suboh et al (16) studied protective effect of some plants used in traditional medicinal practices on erythrocyte fragility triggered by oxidative stress due to $\mathrm{H}_{2} \mathrm{O}_{2}$ administration on erythrocytes in vitro and observed a protective activity. In scientific literature in vivo studies also reveal an attenuation of strength and integrity of erythrocytes due to increased oxidative stress as well as due to reduced anti-oxidant capacity. Kolanjiappana et al found that (17) erythrocytes of cervical cancer patients became more prone to damage due to insufficient anti-oxidant status in osmotic fragility test. Therefore, evaluation of osmotic strength of erythrocytes provides a valuable model in testing possible harmful conditions in vitro as well as in vivo.

In this study it was aimed to test effect of active ingredients of Crocus extracts on erythrocyte fragility and hematological parameters in carbon tetrachloride intoxicated rats.

\section{Materials and methods}

Animals: In this study Wistar albino male rats were placed in standard cages. Room temperature and humidity were kept constant within standard limits. $12 \mathrm{~h}$ dark/12 light period was administered. Water and standard pellet food were given ad libitum. Ethical permission was obtained from Yuzuncu Yil University Animal Experiments Local Committee. All experimental procedures were conducted according to Helsinki Declaration.

Study design: 72 rats were divided into 9 groups $(n=8$ each). In each group following administrations were applied.

Group 1: Control group (standard pellet food + water + i.p. saline injection for 7 days),

Group 2: Olive oil group (1 $\mathrm{ml} / \mathrm{kg}$ i.p. at $7^{\text {th }}$ day),

Group 3: $\mathrm{CCL}_{4}(1 \mathrm{ml} / \mathrm{kg}$ i.p., dissolved in olive oil in $1: 1$ ratio at $\left.7^{\text {th }} \mathrm{day}\right)$,

Group 4: Safran $(100 \mathrm{mg} / \mathrm{kg} / \mathrm{day}$ orally for 7 days),

Group 5: Safranal (100 mg/kg/day i.p. for 7 days,

Group 6: Crocin (100 mg/kg/day i.p. for 7 days),
Group 7: CCL4 $(1 \mathrm{~mL} / \mathrm{kg}$, i.p., dissolved in olive oil in $1: 1$ ratio at $7^{\text {th }}$ day) and Safran (100 $\mathrm{mg} / \mathrm{kg} /$ day i.p. for 7 days),

Group 8: CCL $_{4}(1 \mathrm{~mL} / \mathrm{kg}$ i.p., dissolved in olive oil in 1:1 ratio at $7^{\text {th }}$ day) and Safranal (100 $\mathrm{mg} / \mathrm{kg} / \mathrm{day}$, i.p. for 7 days),

Group 9: $\mathrm{CCL}_{4}(1 \mathrm{~mL} / \mathrm{kg}$ i.p., dissolved in olive oil in 1:1 ratio at $7^{\text {th }}$ day) and Crocin (100 $\mathrm{mg} / \mathrm{kg} / \mathrm{day}$, i.p. for 7 days).

24 hours following $\mathrm{CC}_{44}$ administration ( $8^{\text {th }}$ day) rats were sacrificed. Blood samples were obtained from venous blood under anesthesia.

Hematological measurements: Venous blood was withdrawn into EDTA containing tubes. Number of red blood cells (RBC), hematocrit (HCT) and hemoglobin (HGB) were measured with an automated device suitable for animal studies - Abacus Junior Vet 5, Australia).

Erythrocyte fragility: Osmotic fragility of erythrocytes was assessed with a spectrophotometer at $546 \mathrm{~nm}$ (Prime-Ev, BPC). Blood samples were incubated for a day in ambient temperature. $30 \mu \mathrm{L}$ from erythrocyte package of those incubated blood samples were added onto solutions containing buffers $\left(\mathrm{Na}_{2} \mathrm{HPO}_{4}\right.$ and $\left.\mathrm{NaH}_{2} \mathrm{PO}_{4}\right)$ in order to achieve suitable $\mathrm{pH}$ conditions and different concentrations of $\mathrm{NaCl}(0.4$ and $0.5 \% \mathrm{NaCl})$. After 30 minutes of incubation at room temperature, blood containing solutions were centrifuged at $3000 \mathrm{rpm}$ for 5 minutes. Absorbance of supernatant fractions was evaluated with spectrophotometer (18).

Statistical analysis: Results are presented as mean \pm standard deviation. Kruskal-Wallis and Tukey's tests were performed for statistical analysis.

\section{Results}

Erythrocyte fragility: Erythrocyte fragility values expressed as percentage of hemolysis due to salinity for 0.4 and $0.5 \% \mathrm{NaCl}$ concentrations were found significantly higher for $\mathrm{CCL}_{4}$ compared to control $(\mathrm{p}<0.05)$ (Figure 1).

Hematological parameters: Selected hematological parameters namely RBC, HCT and HGB were assessed. Results state a significant augmentation in red blood cell count in safran administered group $(\mathrm{p}<0.05)$. Other findings for RBC count state an attenuation in crocin group without statistical significance. HCT values were found highest in safran and $\mathrm{CCL}_{4}$ Crocin administered groups. Similarly with HCT values, 
no significant difference was found for HGB in administration groups compared to control. Results of hematological parameters are shown in table 1 .

\section{Discussion}

In this study which aimed to test effect of saffron active ingredients on erythrocyte fragility and some selected hematological parameters in $\mathrm{CCL}_{4}$ intoxicated rats, a significant increase in erythrocyte osmotic fragility in $\mathrm{CCL}_{4}$ administered group and an amelioration with administered ingredients was found. In addition, a significant increase in $\mathrm{RBC}$ value was observed for safran administered group.

Erythrocytes are used extensively in oxidative stress research since they contain hemoglobin and polyunsaturated fatty acids in their membranes (19). CCL $_{4}$ is a toxic xenobiotic and known to increase both oxidative stress and erythrocyte osmotic fragility (20). In experimental procedures a single dose administration of $\mathrm{CCl}_{4}(1 \mathrm{~mL} / \mathrm{kg}$, i.p.) is known to exert erythrocyte damage $i$

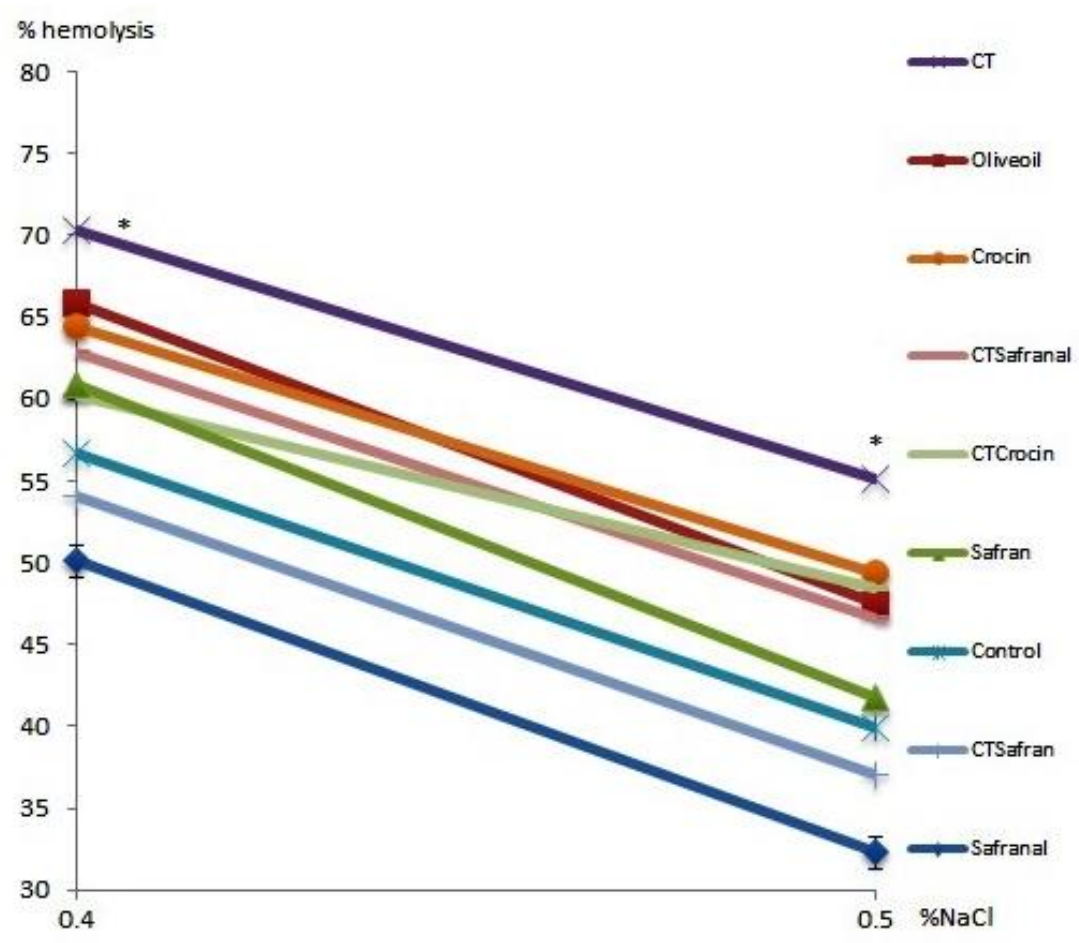

Fig. 1. Effect of CCL4, safran, safranal, crocin and concomitant use of them with CCL4 on erythrocyte osmotic fragility. Values are presented in percent hemolysis. ${ }^{*}=$ statistically significant compared to control $(\mathrm{p}<0.05) . \mathrm{CT}=$ Carbon tetrachloride.

Table 1. Results of different administrations on some selected hematological parameters

\begin{tabular}{lccc}
\hline & RBC $(\times 106 / \mathrm{mm} 3)$ & HCT $(\%)$ & HGB $(\mathrm{g} / \mathrm{dL})$ \\
\hline Control & $7.21 \pm 0.47$ & $46.30 \pm 2.37$ & $14.25 \pm 0.92$ \\
Olive oil & $7.97 \pm 0.23$ & $47.50 \pm 1.42$ & $15.55 \pm 0.35$ \\
CCL $_{4}$ & $8.18 \pm 0.44$ & $50.55 \pm 3.46$ & $16.50 \pm 0.71$ \\
Safran & $8.71 \pm 0.62^{*}$ & $53.45 \pm 4.88$ & $16.50 \pm 0.70$ \\
Safranal & $6.49 \pm 0.25$ & $51.65 \pm 1.07$ & $13.15 \pm 0.49$ \\
Crocin & $7.62 \pm 0.21$ & $46.40 \pm 1.71$ & $15.00 \pm 0.14$ \\
CCL 4 Safran & $8.19 \pm 0.14$ & $50.65 \pm 1.64$ & $15.95 \pm 0.35$ \\
CCL 4 Safranal & $7.68 \pm 0.42$ & $48.90 \pm 4.38$ & $14.90 \pm 0.99$ \\
CCL $_{4}$ Crocin & $8.11 \pm 0.24$ & $53.65 \pm 2.90$ & $16.05 \pm 0.17$ \\
\hline
\end{tabular}

RBC: Red blood cell, HGB: hemoglobin, HCT: hematocrit. Values are presented as mean \pm standard deviation. ( $\mathrm{n}=8$ for each group). CCL4: carbon tetrachloride. Significance is accepted as $\mathrm{p}<0.05$. ${ }^{*}=$ compared to control. 
Wistar albino rats (19). Erythrocyte fragility is an indicator of cellular damage to organism due to exposed chemicals or disease situations. Increased erythrocyte osmotic fragility was observed in experimental hypothyroidism in Sprague Dawley rats (21) and in human sleep apnea patients (22). Some of those disease situations are also known to be related with augmented oxidative stress in patients. Preventing oxidative stress caused by molecules such as $\mathrm{CCL}_{4}$ and protection of erythrocytes against fragility is intensively studied. Research focus on amelioration of this parameter via administered substances which are mostly of natural origin such as plant extracts or active ingredients (23). Anti-hemolytic activity of saffron and its ingredients are also studied. Khalili et al (15) found that extraction of aerial parts of Crocus caspius strongly inhibited $\mathrm{H}_{2} \mathrm{O}_{2}$-induced hemolysis in mice blood. This finding is similar with our results indicating an amelioration of hemolytic effect of $\mathrm{CCL}_{4}$ on erythrocytes.

In this study RBC, HGB and HCT were selected since they are known to be affected by some ingredients of saffron. Such selected hematological parameters in our study revealed no significant effect of $\mathrm{CCL}_{4}$ and other ingredients except safran with a significant increase in RBC count. This finding is contradictory with results of Saba et al (24). They have found microcytic hypochromic anemia due to $\mathrm{CCL}_{4}$ administration. However their administered dosage of $\mathrm{CCL}_{4}$ was higher $(1.25 \mathrm{~mL} / \mathrm{kg})$ compared to ours $(1 \mathrm{~mL} / \mathrm{kg})$. An insignificant attenuation of HGB and HCT were observed due to crocin in a study by ElBeshbishy et al (25). In our study, no such effect was observed in crocin and an insignificant decline in RBC count and HGB value in safranal group was observed. Difference between these two studies may because of administered doses. Dosage of crocin in the mentioned study was 2 times higher $(200 \mathrm{mg} / \mathrm{kg})$ than our dosage (100 $\mathrm{mg} / \mathrm{kg}$ ).

Saffron and its active ingredients are known to exert protective effect against oxidative stress (26) and genotoxicity (27). Therefore it is expected to observe protective effect against damage on somatic cells as well as erythrocytes. In our study saffron active ingredients namely safran, safranal and crocin exerted protective effect on CCL4 induced augmentation in erythrocyte fragility. Longer exposure of such ingredients may also yield significant results on hematological parameters.

Result of this present study reveals a protective effect of saffron active ingredients namely safran, safranal and crocin on $\mathrm{CCL}_{4}$ induced erythrocyte fragility. No significant alteration in selected hematological parameters (RBC, HCT and HGB) due to CCL4 and listed active ingredients except safran may be due to short administration period. Research studies covering more time periods may be useful for assessment of protective effect of saffron ingredients on this model.

\section{References}

1. Kus I, Ogeturk M, Oner H, et al. Protective effects of melatonin against carbon tetrachlorideinduced hepatotoxicity in rats: a light microscopic and biochemical study. Cell Biochem Funct 2005; 23: 169-174.

2. Muriel P, Alba N, Pérez-Alvarez VM, Shibayama M, Tsutsumi VK. Kupffer cells inhibition prevents hepatic lipid peroxidation and damage induced by carbon tetrachloride. Comp Biochem Physiol C Toxicol Pharmacol 2001; 130: 219-226.

3. Manibusan MK, Odin M, Eastmond DA. Postulated carbon tetrachloride mode of action: a review. J Environ Sci Health C Environ Carcinog Ecotoxicol Rev 2007; 25: 185-209.

4. Hong RT, Xu JM, Mei Q. Melatonin ameliorates experimental hepatic fibrosis induced by carbon tetrachloride in rats. World J Gastroenterol 2009; 15: 1452-1458.

5. Liu N, Yang Y, Mo S, Liao J, Jin J. Calcium antagonistic effects of Chinese crude drugs: preliminary investigation and evaluation by $45 \mathrm{Ca}$. Appl Radiat Isot 2005; 63: 151-155.

6. Fatehi M, Rashidabady T, Fatehi-Hassanabad Z. Effects of Crocus sativus petals' extract on rat blood pressure and on responses induced by electrical field stimulation in the rat isolated vas deferens and guinea-pig ileum. J Ethnopharmacol 2003; 84: 199-203.

7. Inoue E, Shimizu Y, Shoji M, et al. Pharmacological properties of N-095,a drug containing red ginseng, polygala root, saffron, antelope horn and aloe wood". Am J Chin Med 2005; 33: 49-60.

8. Nair SC, Kurumboor SK, Hasegawa JH. Saffron chemoprevention in biology and medicine: A review. Cancer Biother 1995; 10: 257-264.

9. Fernandez JA. Biology, biotechnology and biomedicine of saffron. Recent Res Devel Plant Sci 2004: 2127-2159.

10. Papandreou MA, Kanakis CD, Polissiou MG, et al. Inhibitory activity on amyloid-beta aggregation and antioxidant properties of Crocus sativus stigmas extract and its crocin constituents. J Agric Food Chem 2006; 54: 8762-8768.

11. Hosseinzadeh H, Sadeghnia HR. Protective effect of safranal on pentylenetetrazol-induced seizures 
in the rat: Involvement of GABAergic and opioids systems. Phytomedicine 2007; 14: 256-262.

12. Hosseinzadeh $\mathrm{H}$, Ghenaati J. Evaluation of the antitussive effect of stigma and petals of saffron (Crocus sativus) and its components, safranal and crocin in guinea pigs. Fitoterapia 2006; 77: 446448.

13. Sheng L, Qian Z, Zheng S, Xi L. Mechanism of hypolipidemic effect of crocin in rats: crocin inhibits pancreatic lipase. Eur J Pharmacol 2006; 543: 116-122.

14. Hosseinzadeh H, Talebzadeh F. Anticonvulsant evaluation of safranal and crocin from Crocus sativus in mice. Fitoterapia 2005; 76: 722-724.

15. Khalili M, Ebrahimzadeh MA, Safdari Y. Antihaemolytic activity of thirty herbal extracts in mouse red blood cells. Arh Hig Rada Toksikol 2014; 65: 399-406.

16. Suboh SM, Bilto YY, Aburjai TA. Protective effects of selected medicinal plants against protein degradation, lipid peroxidation and deformability loss of oxidatively stressed human erythrocytes. Phytother Res 2004; 18: 280-284.

17. Kolanjiappana K, Manoharana S, Kayalvizhib M. Measurement of erythrocyte lipids, lipid peroxidation, antioxidants and osmotic fragility in cervical cancer patients. Clinica Chimica Acta 2002; 326: 143-149.

18. Pagano M. Faggio C. The use of erythrocyte fragility to assess xenobiotic cytotoxicity. Cell Biochem Funct 2015; 33: 351-355.

19. Makni M, Chtourou Y, Fetoui H, et al. Erythrocyte oxidative damage in rat treated with CC14: protective role of vanillin. Toxicol Ind Health 2012; 28: 908-916.
20. Fujita K. A study on erythrocyte-membrane osmotic resistance and periodontal changes in rats treated with carbon tetrachloride. Shikwa Gakuho 1990; 90: 727-743.

21. Dariyerli N, Toplan S, Akyolcu MC, Hatemi H, Yigit G. Erythrocyte Osmotic Fragility and Oxidative Stress in Experimental Hypothyroidism. Endocrine 2004; 25: 1-5.

22. Ozturk L, Mansour B, Yuksel M, et al. Lipid peroxidation and osmotic fragility of red blood cells in sleep-apnea patients. Clinica Chimica Acta 2003; 332: 83-88.

23. Mojzis J, Nicák A, Guzy J, Kron I, Mirossay L. Effect of stobadine on carbon tetrachlorideinduced erythrocyte membrane changes in rats. Free Radic Biol Med 1998; 24: 1347-1351.

24. Saba AB, Oyagbemi AA, Azeez OI. Amelioration of carbon tetrachloride-induced hepatotoxicity and haemotoxicity by aqueous leaf extract of Cnidoscolus aconitifolius in rats. Niger J Physiol Sci 2010; 28: 139-147.

25. El-Beshbishy HA, Hassan MH, Aly HA, Doghish AS, Alghaithy AA. Crocin "saffron" protects against beryllium chloride toxicity in rats through diminution of oxidative stress and enhancing gene expression of antioxidant enzymes. Ecotoxicol Environ Saf 2012; 83: 47-54.

26. Sebastin Santhosh M, Hemshekhar M, Thushara RM, et al. Vipera russelli venom-induced oxidative stress and hematological alterations: Amelioration by crocin a dietary colorant. Cell Biochem Funct 2013; 31: 41-50.

27. el Daly ES. Protective effect of cysteine and vitamin E, Crocus sativus and Nigella sativa extracts on cisplatin-induced toxicity in rats. J Pharm Belg 1998; 53: 87-93. 